\title{
Myopathy with mitochondrial inclusion bodies: histological and metabolic studies
}

\author{
W. R. SUlaiman, D. DOYle, R. H. JOHNSON, AND S. JENNETT \\ From the University Departments of Neurology and Neuropathology, \\ Institute of Neurological Sciences, Southern General Hospital, Glasgow \\ and the Institute of Physiology, University of Glasgow
}

SYNOPSIS Apparently new information about a metabolic abnormality has been obtained by measuring biochemical and respiratory responses to controlled exercise in a patient with abnormal mitochondria in muscle fibres. A male patient (49 years old) presented with bilateral ptosis of 15 to 20 years' duration and weakness for one to two years. Biopsies from the deltoid and triceps muscles were subjected to histological, histochemical, and electron microscopical examination. Routine histology showed only minor changes; $2-5 \%$ of muscle fibres had pale borders in which there were aggregates of mitochondria and $1-5 \%$ of fibres showed atrophy. Histochemical examination showed increased activity of succinic dehydrogenase in mitochondria and lactate dehydrogenase in cytos plasm. Electron microscopy showed crystalline inclusions in many subsarcolemmal mitochondria Metabolites were studied during and after exercise on an ergometer and revealed remarkable differences from normal. Blood lactate rose to $12.5 \mu \mathrm{mol} / \mathrm{ml}$ and pyruvate to $0.39 \mu \mathrm{mol} / \mathrm{ml}$ compare $\$$ ? with up to 4.0 and $0.16 \mu \mathrm{mol} / \mathrm{ml}$ respectively in controls exercising to a comparable percentage o. capacity. Concentrations of ketone-bodies and free fatty acids fell during and after exercise, while $z$ they rose in the controls. These observations imply a major mitochondrial defect which causeg

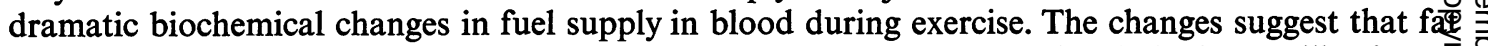
metabolism was accelerated (in this patient) and was related to a block of carbohydrate utilization as. fuel.

Electron microscopy has allowed delineation of abnormalities of intracellular structures including mitochondria. The oculoskeletal myopathies is one group of disorders in which major defects are detectable in this way. These patients present with progressive ptosis, generalized muscle weakness, and sometimes paresis of extraocular muscles. The literature has been reviewed by Morgan-Hughes and Mair (1973) who reported an additional four patients. Although these authors have supplied detailed descriptions of the neuropathological changes which may occur, they did not investigate the metabolic effects of the disorder. They showed histochemical and ultrastructural changes in the mitochondria of muscle fibres. Mitochondria are the sites within the cells where enzyme systems subserving oxidative phosphorylation of both fat and carbohydrate are concentrated, and some authors have suggested that defects in metabolism in these pathways may occur in association with such abnormalities (Bradley et al., 1969). We have had the opportunity of investigating another patient with oculoskeletal myopathy. We have evidence that the neuropathological changes are similar to those described by Morgan-Hughes and Mair (1973) and now report metabolic responses to exercise which have apparently not been investigated previously in patients with these clinical and histological abnormalities.

\section{CASE REPORT}

A.B. (Institute of Neurological Sciences, Glasgow, 옹 807873) was a 49 year old married man with two $\frac{T}{0}$ children, who was employed as a lorry driver. His mother died of carcinoma of the stomach at 62 years. $N$ and his father of myocardial infarction at 67 years. 
TABLE 1

HISTOCHEMICAL REACTIONS OF MUSCLE FIBRES IN PATIENT*

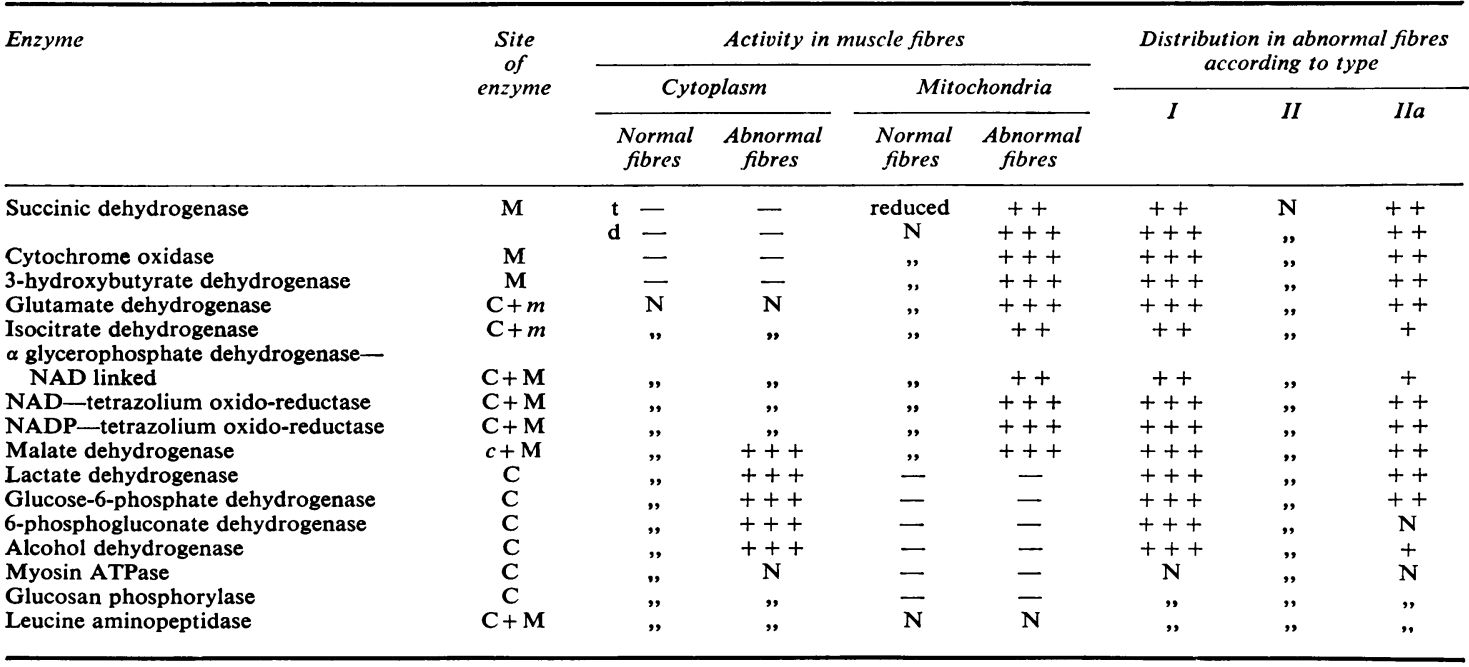

* Abnormalities in the activities of mitochondrial (M) and cytoplasmic (C) enzymes were seen in some type I and IIa fibres.

$(++=$ moderately increased; $+++=$ greatly increased; $N=$ normal activity; $m=$ predominantly mitochondrial; $c=$ predominantly cytoplasmic; $t=$ triceps; $d=$ deltoid.)

He had five siblings, three of whom were well. One died of alcoholic cirrhosis ( 50 years) and the other of 'stomach trouble' (51 years). There was no family history of muscle disease, ptosis, or diabetes. He complained of drooping of his eyelids for many years, and he was aware of trying to lift them with his forehead. He had also had very occasional double vision on lateral gaze for about two to three months. These symptoms were worse later in the day. Photographs indicated that he looked normal at 18 years, but a left ptosis had become obvious at about 33 years. He made no complaint about tiredness when first seen, but later admitted that this had been a problem for one to two years; it was not related to time of day.

His height was $176 \mathrm{~cm}$ and weight $62 \mathrm{~kg}$. There was no obvious muscular wasting. He had wrinkling of his forehead with bilateral ptosis. There was weakness of upward conjugate gaze and slight weakness of conjugate gaze to either side. Convergence was poor. His voice had a nasal quality but the palate moved normally. In the limbs there was no muscle fatiguability but there was slight weakness of both triceps muscles and of the small muscles of both hands. All reflexes were normal. The remainder of the physical examination was negative.

The following investigations were normal: erythrocyte sedimentation rate $(7 \mathrm{~mm} / \mathrm{hr})$, haemoglobin $(14 \cdot 8 \mathrm{~g} / 100 \mathrm{ml})$, white cell count $\left(7,000 / \mathrm{mm}^{3}\right)$, electrolytes $\left(\mathrm{Na}^{+} 141, \mathrm{~K}^{+} 4 \cdot 6, \mathrm{Cl}^{-} 99 \mathrm{mEq} /\right.$ litre $)$,
WR, blood urea $(44 \mathrm{mg} / 100 \mathrm{ml})$, blood sugar $(85 \mathrm{mg} /$ $100 \mathrm{ml})$, protein bound iodine $(5.3 \mu \mathrm{g} / 100 \mathrm{ml})$, electrocardiograph, electroencephalogram, radiographs of skull and chest, and edrophonium bromide (Tensilon) test. Serum creatine phosphokinase was at the upper limit of normal $(101 \mathrm{mU} / \mathrm{ml}$; normal range for laboratory $-100 \mathrm{mU} / \mathrm{ml}$ ). Nerve conduction studies showed normal conduction velocities in right median $(68 \mathrm{~m} / \mathrm{s})$ and ulnar $(54 \mathrm{~m} / \mathrm{s})$ nerves but slight reduction in right lateral popliteal nerve (38 $\mathrm{m} / \mathrm{s}$ ), which was thought to be significant as limb temperature was satisfactory. Electromyography of proximal muscle groups showed an excess of myopathic units (short duration polyphasic units). There was also scanty fibrillation in the right deltoid, and polyphasic fasciculations in the right tibialis anterior and right orbicularis oculi muscles suggesting a concomitant neuropathic disorder.

MUSCLE BIOPSIES Biopsies were taken from the left triceps and the left deltoid muscle under local anaesthesia. They were examined by light microscopy with routine stains. Glycogen distribution was identified by periodic acid Schiff staining (Hotchkiss, 1948) and fat by staining with Oil red $O$ (Lillie and Ashburn, 1943). Specimens were also examined by electron microscopy (Philips 201 electron microscope), goniometry (Philips 301 electron microscope with double tilt goniometry), electron diffraction and 


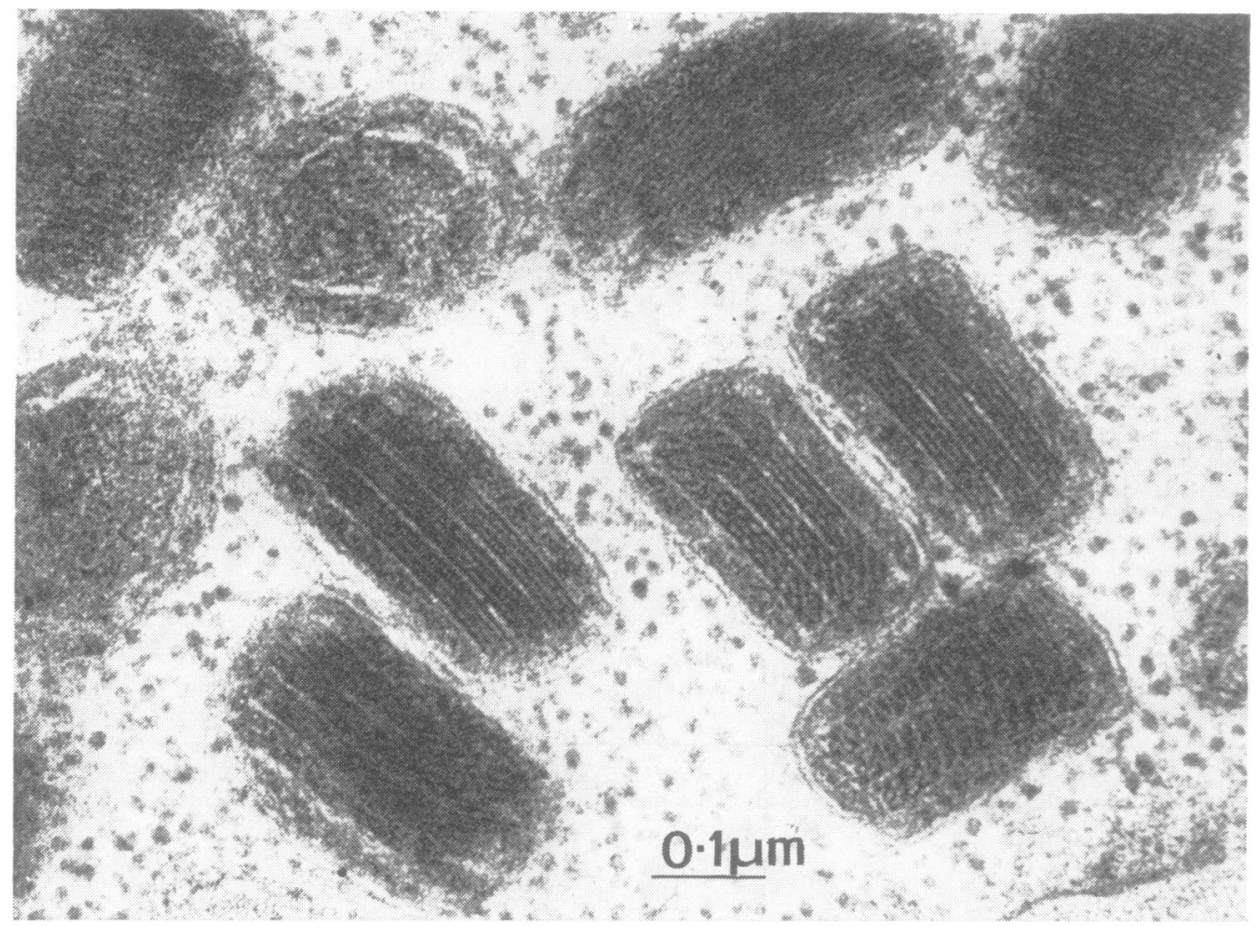

FIG. 1. Electron micrograph of the crystalline inclusion bodies in mitochondria showing the patterns which are determined by the angle of incidence of the electron beam. Two mitochondria are shown which do not contain cystals but have abnormally arranged cristae. $\times 12,500$.

$x$-ray microchemical analysis (Edax-Energy Dispersive Analysis by $x$-ray) with Philips 301 electron microscope. The enzymes shown in Table 1 were demonstrated histochemically. Succinic dehydrogenase was examined by the method of Seligman and Rutenburg (1951); myosin ATPase by that of Padykula and Herman (1955a, b); glucosan phosphorylase by that of Takeuchi and Kuriaki (1955); and leucine aminopeptidase by that of Nachlas et al. (1957). The other enzymes were studied by the methods of Hess et al. (1958). Light microscopy with phase contrast and polarized light revealed virtually normal muscle and the abnormalities seen in stained preparations were minor. In the specimen from the left triceps muscle about $5 \%$ of the fibres were atrophic, some being exceptionally small in cross-sectional area $(20 \mu \mathrm{m})$ with clusters of nuclei. In atrophic fibres there were also some nuclei which were larger than normal ( $15 \mu \mathrm{m}$ diameter) and these had very large nucleoli ( $5 \mu \mathrm{m}$ diameter). Some obviously abnormal fibres (approximately $2 \%$ of total) had unusually pale borders which had abnormal mitochondrial aggregates. The nuclei and nucleoli were larger in these areas. In some areasmany of the fibres had internally placed nuclei but ${ }^{+}$ the remaining fibres appeared normal. Longitudinalo section showed that some nuclei were concentrated close to capillaries, these nuclei appearing largerō than normal. The changes in the specimen from theo left deltoid muscle were similar but only $1 \%$ of the fibres were atrophic. Atrophic fibres appeared in $\vec{F}$ groups of up to six but no supporting evidence of 3 denervation was found in preparations displaying? motor end plates and terminal innervation. There was a larger proportion of fibres with pale borders in this specimen than in that from triceps (about $5 \%$ ). In longitudinal sections large nuclei were frequently: seen close to capillaries. In both specimens glycogen 3 . was found to be reduced in all fibres. The concentration of fat in type I fibres was reduced and it was virtually absent from type II fibres: the fat which ${ }_{0}$ remained was mainly peripheral in the fibres.

ELECTRON MICROSCOPY Electron microscopy (EM) of the specimens from deltoid and triceps revealed noo normal mitochondria (Fig. 1). The least abnormality 
was the arrangement of cristae in concentric circles in the mitochondria rather than transversely as is found normally. Some mitochondria also contained crystal-like inclusions. These mitochondria were most numerous in the pale peripheral borders of the abnormal fibres seen on light microscopy. The crystals were invested by the inner mitochondrial membrane, which was not incorporated in their structure. The crystals varied in length from 0.2 to $5 \mu \mathrm{m}$ and were slightly curved. They were sometimes square but usually oblong. Each crystal consisted of bands about $0.04 \mu \mathrm{m}$ in width separated from

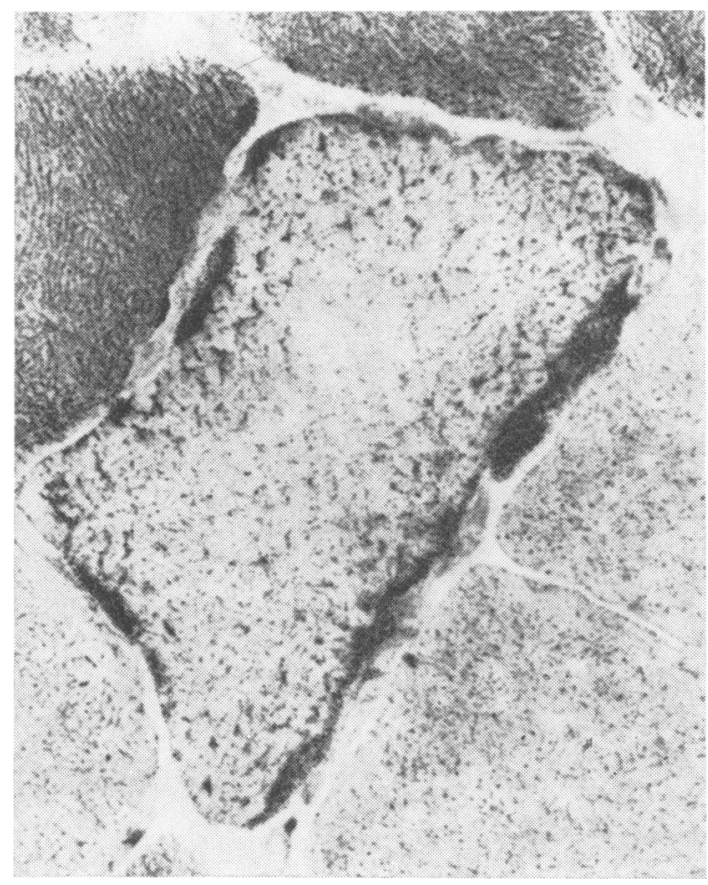

FIG. 2. Abnormal succinic dehydrogenase activity in a type I muscle fibre. The intense zones of peripheral activity were characteristic of the abnormal fibres and in these areas the intramitochondrial crystals were found. $\times 700$.

adjacent bands by a clear region $0.008 \mu \mathrm{m}$ across. The bands had light and dark longitudinal stripes $(0.008 \mu \mathrm{m}$ wide). Although the majority of crystals had such a pattern, in some the bands were arranged obliquely and others had a grid-like structure. Goniometry confirmed that some of the crystals were curved and it was possible to show that the differences in the appearances of the bands depended upon the angle of incidence of the electron beam on the crystal. Electron diffraction and microchemical $x$-ray analysis were non-contributory because of the low mass of the crystals. EM confirmed that there was a general reduction in the fat content of the muscle fibres.

HISTOCHEMISTRY Histochemical examination with myosin ATPase showed fibres of types I, II, and IIa in the usual distribution. Fibre typing was more difficult with other enzymes. Marked abnormalities were observed in fibres of types I and IIa among which $20 \%$ of fibres were affected. No abnormalities were found in type II fibres. Abnormalities were principally seen in the activities of mitochondrial or predominantly mitochondrial enzymes but there were also changes in several enzymes in cytoplasm. In the biopsy specimen from triceps there was a general reduction in the activity of succinic dehydrogenase but there was a peripheral zone of considerably increased activity in type I and type IIa fibres. In the biopsy specimen from deltoid the activity of succinic dehydrogenase was also increased peripherally in type I and type IIa fibres (Fig. 2). Several other mitochondrial enzymes showed increased activity and similar changes were observed in cytoplasmic enzymes, including lactate dehydrogenase (Table 1).

SKIN BIOPSIES Biopsies of skin were taken at the same time as the muscle biopsies. No histological changes were found and on EM all mitochondria were normal.

BIOCHEMICAL RESPONSE TO EXERCISE The biochemical changes during exercise were studied on two occasions, during and after a 30 minute period of exercise. The results were compared with those from six controls-normal male subjects aged 28 to 44 years. The investigations were performed between $09.00 \mathrm{hr}$ and $11.00 \mathrm{hr}$ after an overnight fast. A catheter was placed in an antecubital vein and flushed with saline. Two resting samples of blood were taken. Work was performed for 30 minutes at $600 \mathrm{kpm}$ on a bicycle ergometer (Elema Schönander constant load ergometer, EM369). Heart rate was recorded during the exercise and for an additional 15 minutes, using miniature chest electrodes with an electrocardiograph. Blood samples were taken at five minute intervals during exercise and then at 15,30 , 60, and 90 minutes afterwards. The controls were investigated in a similar way: their work load $(600 \pm 100 \mathrm{kpm})$ was adjusted so that the increased heart rates were similar to that in the patientnamely, between 150 and $170 / \mathrm{min}$. In the second investigation pulmonary ventilation was measured 


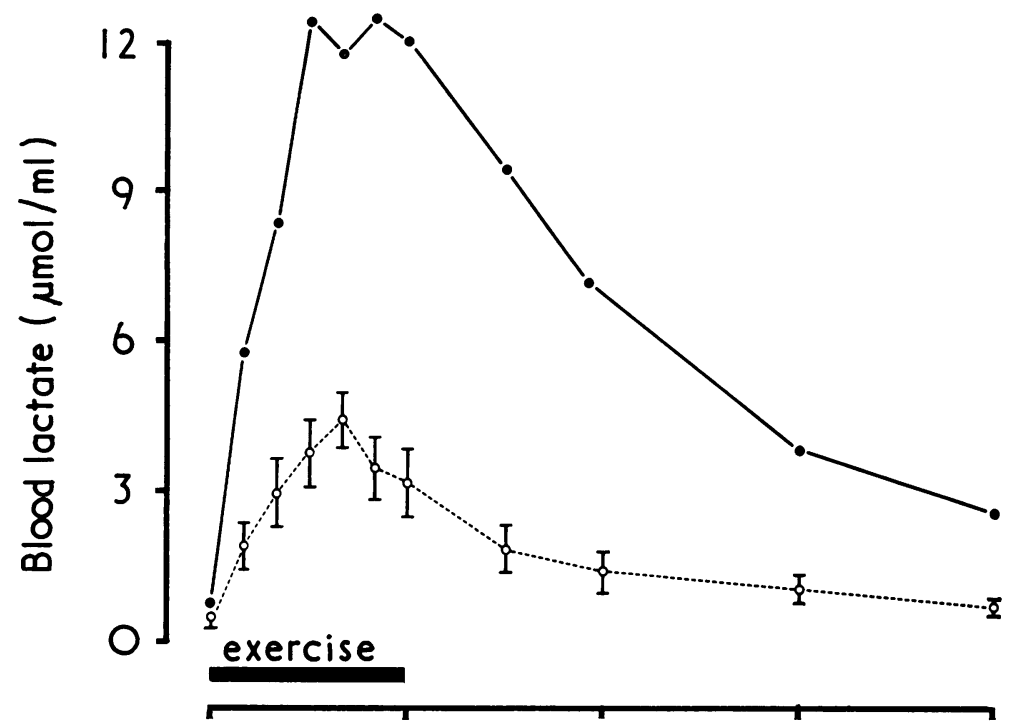

FIG. 3. Blood lactate and pyruvate $(\mu \mathrm{mol} / \mathrm{ml})$ in the patient (O-O) and six normal control subjects

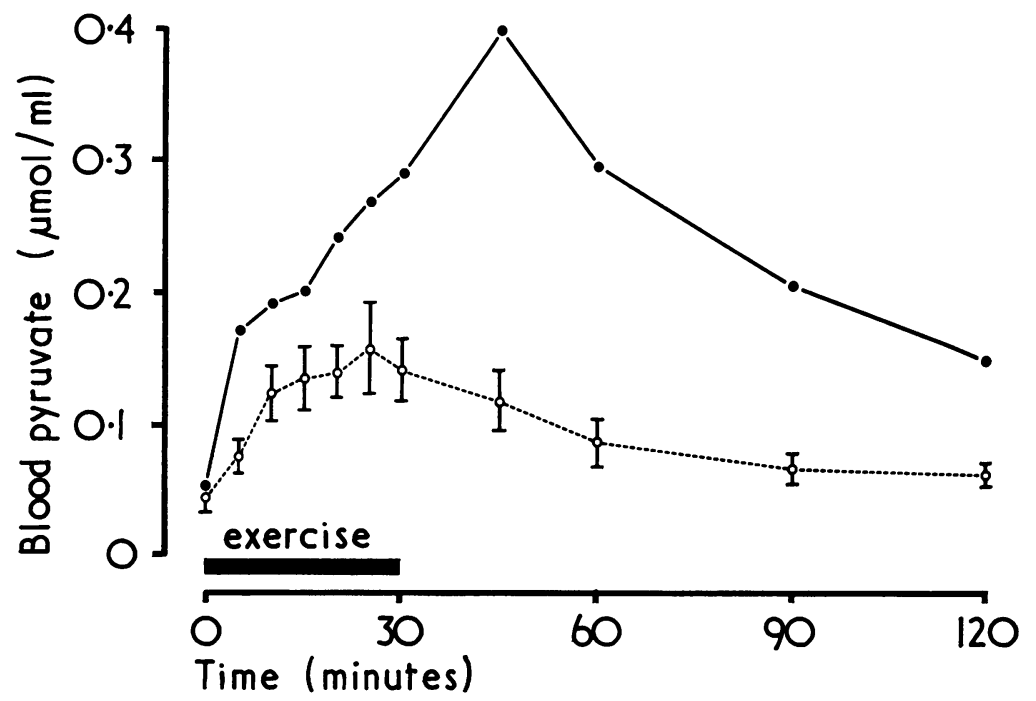
$(\bigcirc--\bigcirc)( \pm$ SEM $)$ during and after 30 minutes of exercise, indicated by the solid bar.

and expired air was collected in a Douglas bag and analysed for $\mathrm{O}_{2}$ and $\mathrm{CO}_{2}$ to determine oxygen consumption, carbon dioxide output, and respiratory exchange ratio ( $R)$. Measurements were made at rest and during exercise and recovery.

Each blood sample was divided into parts. Five millilitres were deproteinized by addition to $5 \mathrm{ml} \mathrm{10 \%}$ perchloric acid. The remainder was heparinized and the plasma separated by centrifugation. All specimens were then stored in ice. The deproteinized samples were analysed for glucose (Bergmeyer and Bernt, 1963), lactate and pyruvate (Hohorst et al., 1959), glycerol (Kreutz, 1962), acetoacetate and 3- hydroxybutyrate (Williamson et al., 1962). The plasma sample was analysed for free fatty acids (FFA) by a colorimetric method after chloroform extraction (Itaya and $\mathrm{Ui}, 1965)$, for human growth hormone (HGH), by radioimmunoassay using two antibodies (Morgan and Lazarow, 1963), and for immunoreactive insulin (IRI) by a charcoal immunoassay (Hunter, 1969; Hunter and Ganguli, 1971). The standards used were MRC Standard A for HGH and Wellcome MR71 for IRI.

Glucose concentrations (Fig. 4) at rest were similar in the patient and the controls but there was a $N$ marked difference during and after exercise. The 

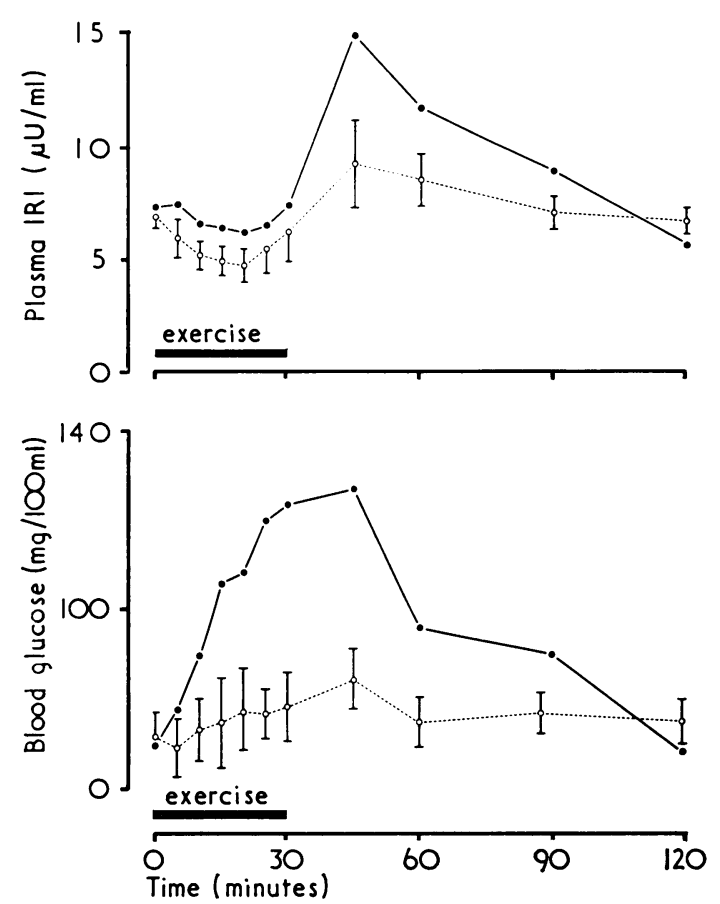

FIG. 4. Plasma IRI $(\mu \mathrm{U} / \mathrm{ml})$ and blood glucose ( $\mathrm{mg} /$ $100 \mathrm{ml})$ in the patient $\left({ }_{-}\right)$and six normal control subjects $(\bigcirc---\bigcirc)( \pm S E M)$ during and after 30 minutes of exercise, indicated by the solid bar.

blood glucose rose to $135 \mathrm{mg} / 100 \mathrm{ml}$ in the patient at the end of exercise, whereas there was no significant change in the controls.

Lactate concentrations (Fig. 3) at rest were similar but with exercise there was a rapid elevation in the patient to $12.5 \mu \mathrm{mol} / \mathrm{ml}$ compared with $4.0 \mu \mathrm{mol} / \mathrm{ml}$ in the controls. The plasma concentration in the patient declined after exercise but had not returned to the resting value 90 minutes after the end of exercise.

Pyruvate concentrations (Fig. 3) at rest were similar and the exercise caused a rapid elevation. The highest plasma concentration in the patient $(0.39$ $\mu \mathrm{mol} / \mathrm{ml}$ ) was achieved 15 minutes after the end of exercise. After this the concentration declined but had not returned to the resting value by the end of the investigation. The maximum lactate/pyruvate ratio was greatly elevated in the patient $(400 \%$ above resting) compared with the controls $(230 \%$ above resting).

Plasma free fatty acids (FFA) concentrations (Fig. 5) at rest in the patient were $80 \%$ higher than in the controls on the first occasion but similar on the
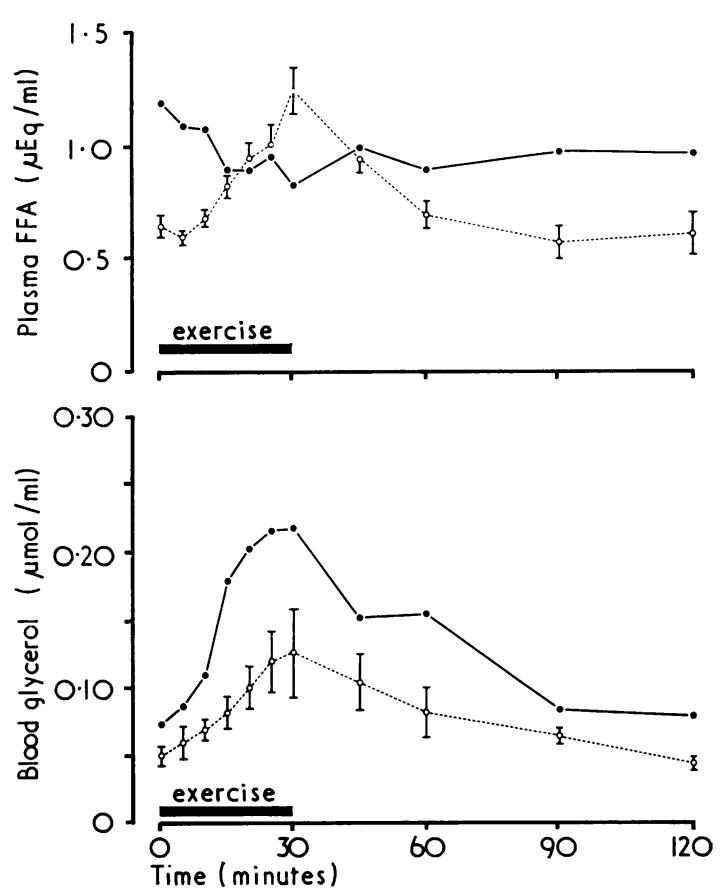

FIG. 5. Plasma FFA $(\mu E q / m l)$ and blood glycerol $(\mu \mathrm{mol} / \mathrm{ml})$ in the patient $\left({ }_{-}\right)$and six normal control subjects $(\bigcirc---\bigcirc)( \pm S E M)$ during and after 30 minutes of exercise, indicated by the solid bar.

second. On both occasions concentrations declined during exercise compared with the controls, in which they rose.

Blood glycerol concentration (Fig. 5) at rest in the patient was higher than in the controls on the first occasion but similar on the second. In both studies it rose to nearly twice the mean level in the controls by the end of exercise. The concentration then declined in both the patient and the controls, the resting values being achieved by the end of the investigations.

Total blood ketone-body concentrations (Fig. 6) at rest in the patient were five times higher than in the controls on the first occasion and within the normal range on the second. The concentrations fell during and after exercise whereas they rose in the controls. On the first occasion the 3-hydroxybutyrate/acetoacetate ratio for the patient was 2.24 before exercise and rose to 4.40 after five minutes of exercise and then fell progressively to $1 \cdot 0,30$ minutes after exercise. In the patient's second exercise investigation the changes were similar. In the controls the mean value at rest was $2 \cdot 16$, and it fell to 1.36 after five minutes of 


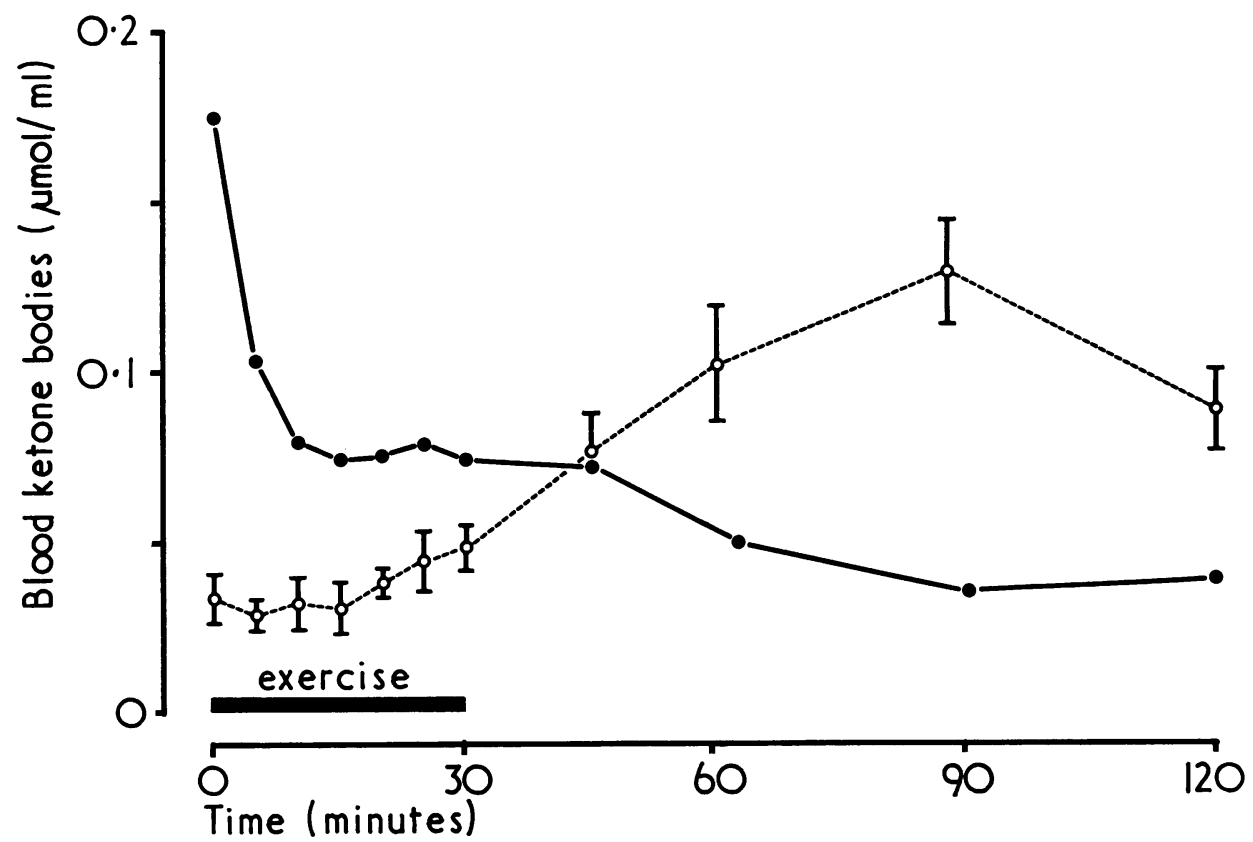

FIG. 6. Blood ketone-bodies (3-hydroxybutyrate+acetoacetate; $\mu \mathrm{mol} / \mathrm{ml}$ ) in the patient $(O-O)$ and six normal control subjects $\left(\mathrm{O}_{--}\right)( \pm S E M)$ during and after 30 minutes of exercise, indicated by the solid bar.

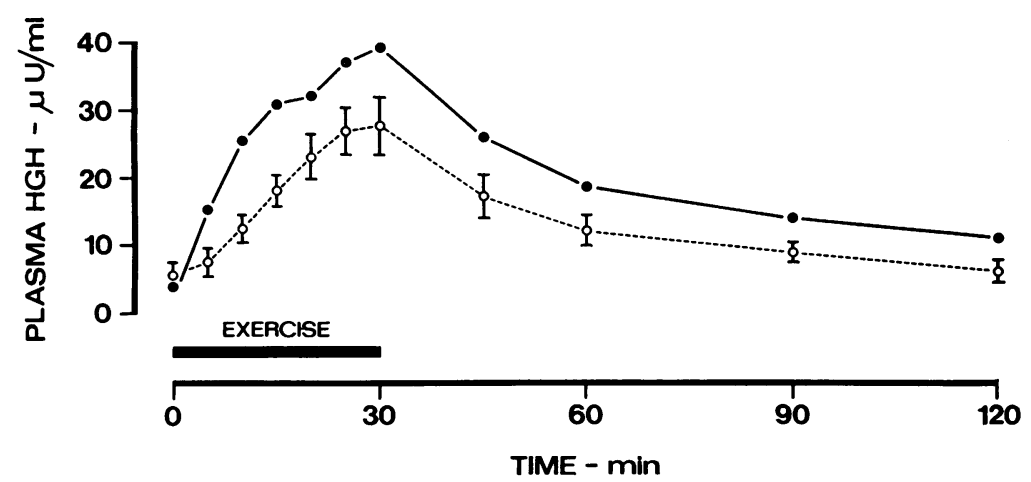

FIG. 7. Plasma $\mathrm{HGH}$ $(\mu \mathrm{U} / \mathrm{ml})$ in the patient $(-1)$ and six normal control subjects $(\mathrm{O}---\mathrm{O})$ $( \pm S E M)$ during and after 30 minutes of exercise, indisated by the solid bar.

exercise. After 30 minutes of exercise it was 2.83 and 30 minutes later it had risen to $3 \cdot 8$.

Plasma immunoreactive insulin (IRI) concentrations (Fig. 4) at rest were similar but exercise caused a fall in plasma IRI in all studies. The fall was greater in the controls after 20 minutes of exercise. After this the concentrations rose, both in the remaining part of exercise and for 15 minutes afterwards. The concentration was much greater 15 minutes after exercise in the patient $(200 \%$ of resting) than in the controls ( $133 \%$ of resting). The concentrations returned to resting values by the end of the investigations.

Plasma human growth hormone $(H G H)$ concentrations (Fig. 7) at rest were similar, but with exercise there was a rapid elevation in the patient to 40 $\mu \mathrm{U} / \mathrm{ml}$ compared with 27 in the controls. The concentrations then declined but had not returned to the resting value by the end of the investigations.

Oxygen consumption at rest was $240 \mathrm{ml} / \mathrm{min}$. The 
values at six, 20, and 30 minutes during exercise were $1.54 \mathrm{l} / \mathrm{min}, 1.38 \mathrm{l} / \mathrm{min}$, and $1.45 \mathrm{l} / \mathrm{min}$. The oxygen consumption had returned to normal 20 minutes after the end of exercise. $R$ was 1.04 while resting before exercise, indicating hyperventilation, and fell progressively during exercise to a minimum of 0.74 at the end. The value 20 minutes afterwards was 0.85 (Table 2).

\section{TABLE 2}

CHANGES IN HEART RATE, VENTILATION, OXYGEN CONSUMPTION, AND RESPIRATORY EXCHANGE RATIO (R) IN PATIENT WITH MITOCHONDRIAL STRUCTURAL ABNORMALITIES*

\begin{tabular}{lccccc}
\hline & $\begin{array}{c}\text { Bcfore } \\
\text { exercise }\end{array}$ & $\begin{array}{c}6-8 \\
\text { min }\end{array}$ & $\begin{array}{c}20-22 \\
\text { min }\end{array}$ & $\begin{array}{c}28-30 \\
\text { min }\end{array}$ & $\begin{array}{c}20 \text { min } \\
\text { min } \\
\text { after }\end{array}$ \\
\hline $\begin{array}{l}\text { Heart rate } \\
\begin{array}{l}\text { Ventilation } \\
\text { ATPS 1/min }\end{array}\end{array}$ & 76 & 150 & 168 & 174 & 100 \\
$\begin{array}{c}\text { Oxygen con- } \\
\text { sumption }\end{array}$ & $11.0 \dagger$ & 49.3 & 48.5 & 54.5 & 9.5 \\
STPD 1/min & 0.24 & 1.54 & 1.38 & 1.45 & 0.19 \\
R & $1.04 \dagger$ & 0.9 & 0.74 & 0.74 & 0.85 \\
\hline
\end{tabular}

* The heart rate suggests that he was at nearly $80 \%$ ํ을 oxygen consumption is relatively low.

$\dagger$ Hyperventilating: end-expired $\mathrm{CO}_{2} 30$ Torr.

BIOCHEMICAL RESPONSE TO EXERCISE AFTER NICOTINIC ACID The biochemical changes during exercise were also studied 15 minutes after ingestion of nicotinic acid (200 $\mathrm{mg})$. The patient exercised for 30 minutes at $600 \mathrm{kpm}$ and the arrangements were similar to those on the previous occasion when ventilatory studies were also carried out. Heart rate changes were the same as those in the previous investigations of exercise (maximum 170/min). The average exercise oxygen consumption was also similar $(1.43 \mathrm{l} / \mathrm{min})$. The major difference was in blood glycerol which was depressed at rest by nicotinic acid (from 0.06 to $0.03 \mu \mathrm{mol} / \mathrm{ml}$ ) and rose to $0.05 \mu \mathrm{mol} / \mathrm{ml}$ only during exercise. It then rose during recovery but even then the maximum value was $0.10 \mu \mathrm{mol} / \mathrm{ml} 45 \mathrm{~min}$ (compare Fig. 5). There was also a marked reduction in the blood glucose concentrations observed during and after exercise (maximum $110 \mathrm{mg} / 100 \mathrm{ml}$ ) and maximum blood lactate and pyruvate were also lower $(9.87 \mu \mathrm{mol} / \mathrm{ml}$ and $0.34 \mu \mathrm{mol} / \mathrm{ml}$ respectively). Plasma FFA declined during exercise (lowest concentration 0.48 $\mu \mathrm{eq} / \mathrm{ml}$ ). Total ketone-bodies showed some depression during exercise but rose to $0 \cdot 10 \mu \mathrm{mol}$ at $45 \mathrm{~min}$ afterwards. Growth hormone changes were similar (maximum $36.0 \mu \mathrm{U} / \mathrm{ml}$ ). The gas exchanges studies showed the same high $R$ value at rest (1.05) but reduction was less marked during and after exercise: 0.86 at the end of exercise and 0.92-0.95 in the following $30 \mathrm{~min}$.

EFFECT OF HEPARIN UPON LIPOLYSIS The investigations were carried out in the morning after an overnight fast according to the method of Fineburg et al. (1972). Corn oil (60 g) which had been emulsified with egg albumen (15 g) was given orally. This was followed three hours later by an intravenous injection of heparin $(50 \mathrm{mg})$. Venous blood samples were taken before ingestion of the corn oil, at 30 minute intervals and then at 15 minute intervals after the injection of heparin for a further two hours. The test was repeated on another occasion omitting the corn oil. The blood samples were analysed for FFA and ketone-bodies (acetoacetate plus 3-hydroxybutyrate) as already described. After the ingestion of the corn oil, plasma FFA concentrations remained unchanged and just before the injection of heparin the concentration was $0.80 \mu \mathrm{Eq} / \mathrm{l}$. The concentration 45 minutes after the injection of heparin was $2.4 \mu \mathrm{Eq} / 1$ and it then fell to a value of $1.8 \mu \mathrm{Eq} / 125$ minutes later. In the control investigation on the patient, injection of heparin alone also caused a rise in the concentrations of FFA, but this was less than that obtained after ingestion of corn oil. The rise in FFA concentrations after heparin was associated with a considerable rise of total ketone bodies.

GLUCOSE TOLERANCE TEST A standard glucose tolerance test was performed after an overnight fast. Glucose (50 g) was given orally and blood samples were obtained at 30 minute intervals for $2 \frac{1}{2}$ hours. Lactate, pyruvate, glucose, and plasma IRI were estimated as in the exercise investigation. The rise and the subsequent fall of both glucose and plasma IRI were similar to those of normal subjects. The tolerance to a glucose load was therefore normal in the patient.

\section{DISCUSSION}

Abnormal muscle mitochondria have been reported in several apparently unrelated conditions. The first report of a muscle disorder with abnormal mitochondria was made in 1959 when increased metabolism was found. The patient's mitochondria contained large crystalline inclusions (Ernster et al., 1959; Luft et al., 1962). Mitochondrial abnormalities have been reported in children (Shy et al., 1966; Jerusalem et al., 1973) but studies showed no significant increases in metabolic rates. In one of these, 
'megaconial myopathy', rectangular inclusion bodies were observed in the muscle mitochondria. Mitochondrial inclusions have also been reported in the skeletal muscle of adults (Shafiq et al., 1967; Bradley et al., 1969), but these reports did not include assessments of the effect of the muscle disorder upon metabolism.

The present patient had an abnormal metabolic response to exercise compared with controls. Concentrations of lactate and pyruvate rose during exercise to values above those observed in the controls. There was also a rapid rise in blood glucose concentration. These observations suggest that, although glycolysis was proceeding, there was a block to complete oxidation of carbohydrate via acetyl $\mathrm{CoA}$ and the tricarboxylic acid cycle.

The patient's lactate/pyruvate ratio, during the first part of exercise, rose above the ratios observed in the controls. Some elevation is the usual response and is probably due to a rapid fall in the ratio of cytoplasmic nicotinamide adenine dinucleotide (NAD) and reduced nicotinamide adenine dinucleotide (NADH) (Krebs, 1967). This cytoplasmic activity is normally linked to the concentration of NAD and NADH in mitochondria but may be independent (Devlin and Bedell, 1960). These changes in the mitochondria may be reflected in the ratio of the concentrations of 3-hydroxybutyrate/acetoacetate in the blood (Williamson et al., 1967). In the patient this ratio first rose and then fell, whereas the converse was observed in the controls. Such findings are obtained with relative cellular hypoxia (Alberti et al., 1972). The changes in these ratios are therefore in keeping with the suggestion already made of a block of oxidative metabolism for carbohydrate.

There was also a much greater rise in blood glycerol concentration in the patient compared with the controls suggesting greater fat mobilization in the patient. Lipolysis results in production not only of glycerol but also FFA. The rise in the concentration of plasma FFA during exercise which occurred in the controls, and is the normal finding, was, however, absent in the patient. Tests of lipoprotein lipase activity had shown that there was no block in the normal production of FFA from plasma triglycerides suggesting that normal transport of fat was occurring. The depression of plasma FFA in the patient during exercise may therefore have been due to either greater catabolism of FFA or to re-esterification to fat. There was no evidence from the biopsies that deposition of fat was occurring excessively in the muscles studied. Normally ketone-body concentrations rise during the post-exercise period (Courtice and Douglas, 1936; Johnson et al., 1969) but this change was absent in the patient. The blockage of carbohydrate metabolism could result from increased fat oxidation to acetyl CoA, a process which is known to block further pyruvate oxidation (Garland and Randle, 1964) and cause accumulation of pyruvate and lactate. This would also account for some of the elevation of glycerol, for this is normally metabolized through the glycolytic pathway via $\alpha$-glycerophosphate.

The rapid rise of blood glucose implies both decreased carbohydrate utilization during exercise and also active glucose production by theo liver. Pathways subserving carbohydrate storage as glycogen were normal, however, as adduced: from the normal glucose tolerance test. The block of carbohydrate metabolism did not prevent the patient exercising and it is probable that energy production depended upon metabolism of fat, as mobilization was occurring and yet there was no accumulation of FFA during exercise and of ketone-bodies after exercise. Additional support for the conclusion that fat was actively metabolized by the patient was the finding that the patient had a relatively low $R$ $\left(\mathrm{CO}_{2}\right.$ production $/ \mathrm{O}_{2}$ consumption) during exercise. $\mathbf{R}$ often rises in severe exercise to a value greater than $1 \cdot 0$. For this patient the exercise was severe relative to his capacity. The value above unity before the investigation was due to hyperventilation but it would be unlikely that this would have driven off so much $\mathrm{CO}_{2}$ before exercise as to account for the low $\mathrm{R} 30$ minutes later. Further evidence for active mobilization of fat as fuel during exercise by the patient was obtained from the study with nicotinic acid. Nicotinic acid is known to block fat mobilization (Carlson and Orö, 1962). The lower values of FFA and glycerol and higher $R$ values we obtained after nicotinic acid during exercise by the patient are in keeping with the conclusion that fat mobilization, although active in the other studies, was blocked by the nicotinic acid. This argument is also supported by the histochemical 
findings of increased activities of enzymes involved in oxidative metabolism such as succinic dehydrogenase and cytochrome oxidase in the abnormal mitochondria.

There were also differences in the hormonal responses to exercise of the patient compared with the controls. Plasma IRI concentration was depressed to a lesser extent during exercise in the patient compared with the controls and he had a greater increase after exercise. During exercise there is an increase in circulating catecholamines (von Euler and Hellner, 1952), which may explain the failure of the increased glucose concentration in the patient to stimulate insulin release, as adrenaline and noradrenaline inhibit insulin release (Kris et al., 1966; Porte and Williams, 1966). The higher concentrations of plasma IRI in the patient compared with controls after exercise could, however, be related to the increased blood glucose as concentrations of blood catecholamines return rapidly to normal, the fall being of the order of $60 \%$ in five minutes (Johnson et al., 1974).

Plasma HGH concentrations were higher in the patient during exercise. It has been suggested that HGH causes lipolysis during exercise and enhances the availability of FFA (Hunter et al., 1965) and therefore the difference in FFA response to exercise in our patient compared with the controls may have been related to the differences in $\mathrm{HGH}$ concentration. Although studies of patients with hypopituitarism have shown that it is not essential for FFA release (Johnson et al., 1971), it does appear to cause FFA release in some situations (Johnson et al., 1973).

There appear to be considerable differences in the metabolic effects of disorders in which abnormal mitochondria are found. The patient with myopathy described by Bradley et al. (1969) had mitochondrial changes on EM which appeared similar to those in our patients. However, in contrast, they found excessive fat in muscle fibres. The two patients described by Coleman et al. (1967) had increased activity of succinic dehydrogenase and other enzymes but no EM studies were reported. These patients, however, also had abnormal accumulation of fat in muscle fibres. Other patients with excess fat in muscle fibres have been described by Worsfold et al. (1973) and in vitro studies of mitochondria from these patients showed that oxidative metabolism was depressed. Mitochondrial aggregates have also been described by Engel (1964) in the muscle fibres from three patients, but these mitochondrial aggregates lacked succinic dehydrogenase activity, thus differing from the abnormal mitochondria in our patient. The patient described by Luft et al. (1962) did have increased metabolic activity and they considered that this occurred in spite of a defect in mitochondrial enzyme organization. The increased fat metabolism during exercise which we now report is compatible with their findings.

Our observations indicate that exercise provides a useful tool for examining the metabolism of abnormal mitochondria. An abnormal metabolic response to exercise has been found and we suggest that studies of further patients may allow delineation of specific patterns of metabolism of value in diagnosis.

We thank the patient and the subjects for their cooperation and Professor J. A. Simpson, Professor H. Adams, and Professor R. M. S. Smellie for encouragement. We also thank Dr. J. P. Ballantyne for electromyography studies and $\mathrm{Mr}$ Gentles and Mr Terras for skilled technical help. We are grateful to the Scottish Hospital Endowments Research Trust, the Scottish Home and Health Department, the National Fund for Research into Crippling Diseases, and the Muscular Dystrophy Group of Great Britain for financial support.

\section{REFERENCES}

Alberti, K. G. M. M., Darley, J. H., Emerson, P. M., and Hockaday, T. D. R. (1972). 2,3-Diphosphoglycerate and tissue oxygenation in uncontrolled diabetes mellitus. Lancet, 2, 391-395.

Bergmeyer, H. U., and Bernt, E. (1963). Determination of glucose oxidase and peroxidase. In Methods of Enzymatic Analysis, pp. 123-130. Edited by H. U. Bergmeyer. Academic Press: New York.

Bradley, W. G., Hudgson, P., Gardner-Medwin, D., and Walton, J. N. (1969). Myopathy associated with abnormal lipid metabolism in skeletal muscle. Lancet, 1, 495-498.

Carlson, L. A., and Orö, L. (1962). The effect of nicotinic acid on the plasma free fatty acids. Demonstration of a metabolic type of sympathicolysis. Acta Medica Scandinavica, 172, 641-645.

Coleman, R. F., Nienhuis, A. W., Brown, W. J., Munsat, T. L., and Pearson, C. M. (1967). New myopathy with mitochondrial enzyme hyperactivity. Journal of the American Medical Association, 199, 624-630.

Courtice, F. C., and Douglas, C. G. (1936). The effects of prolonged muscular exercise on the metabolism. Proceedings of the Royal Society, B, 119, 381-439.

Devlin, T. M., and Bedell, B. H. (1960). Effect of aceto- 
acetate on the oxidation of reduced diphosphopyridine nucleotide by intact rat liver mitochondria. Journal of Biological Chemistry, 235, 2134-2139.

Engel, W. K. (1964). Mitochondrial aggregates in muscle disease. Journal of Histochemistry and Cytochemistry, 12, 46-48.

Ernster, L., Ikkos, D., and Luft, R. (1959). Enzymic activities of human skeletal muscle mitochondria: a tool in clinical metabolic research. Nature, 184, 1851-1854.

Euler, U. S. von, and Hellner, S. (1952). Excretion of noradrenaline and adrenaline in muscular work. Acta Physiologica Scandinavica, 26, 183-191.

Fineberg, S. E., Horland, A. A., and Merimee, T. J. (1972). Free fatty acid concentrations and growth hormone secretion in man. Metabolism, 21, 491-498.

Garland, P. B., and Randle, P. J. (1964). Regulation of glucose uptake by muscle. 10. Effects of alloxan-diabetes, starvation, hypophysectomy and adrenalectomy, and of fatty acids, ketone bodies and pyruvate, on the glycerol output and concentrations of free fatty acids, long-chain fatty acyl-coenzyme A, glycerol phosphate and citratecycle intermediates in rat heart and diaphragm muscles. Biochemical Journal, 93, 678-687.

Hess, R., Scarpelli, D. G., and Pearse, A. G. E. (1958). Cytochemical localization of pyridine nucleotide-linked dehydrogenases. Nature, 181, 1531-1532.

Hohorst, H. J., Kreutz, F. H., and Bücher, T. (1959). Ueber Metabolitgehalte und Metabolit-Konzentrationen in der Leber der Ratte. Biochemische Zeitschrift, 332, 18-46.

Hotchkiss, R. D. (1948). A microchemical reaction resulting in the staining of polysaccharide structures in fixed tissue preparations. Archives of Biochemistry, 16, 131-141.

Hunter, W. M. (1969). Control of specificity in the radioimmunoassay. In Protein and Polypeptide Hormones, pp. 5-13 and pp. 551-553. Edited by M. Margoulies. International Congress Series No. 161, Excerpta Medica: Amsterdam.

Hunter, W. M., Fonseka, C. C., and Passmore, R. (1965). Growth hormone; important role in muscular exercise in adults. Science, 150, 1051-1053.

Hunter, W. M., and Ganguli, P. C. (1971). The separation of antibody bound from free antigen. In Radioimmunoassay Methods, pp. 243-257. Edited by K. E. Kirkham and W. M. Hunter. Churchill Livingstone: Edinburgh.

Itaya, K., and Ui, M. (1965). Colorimetric determination of free fatty acids in biological fluids. Journal of Lipid Research, 6, 16-20.

Jerusalem, F., Angelini, C., Engel, A. G., and Groover, R. V. (1973). Mitochondria-lipid-glycogen (MLG) disease of muscle. Archives of Neurology, 29, 162-169.

Johnson, R. H., Park, D. M., Rennie, M. J., and Sulaiman, W. R. (1974). Hormonal responses to exercise in racing cyclists. Journal of Physiology, 241, 23-25P.

Johnson, R. H., and Rennie, M. J. (1973). Changes in fat and carbohydrate metabolism caused by moderate exercise in patients with acromegaly. Clinical Science, 44, 63-71.

Johnson, R. H., Rennie, M. J., Walton, J. L., and Webster, M. H. C. (1971). The effect of moderate exercise on blood metabolites in patients with hypopituitarism. Clinical Science, 40, 127-136.

Johnson, R. H., Walton, J. L., Krebs, H. A., and Williamson, D. H. (1969). Metabolic fuels during and after severe exercise in athletes and non-athletes. Lancet, 2, 452-455.
Krebs, H. A. (1967). The redox state of nicotinamide adenine dinucleotide in the cytoplasm and mitochondria of rat liver. Advances in Enzyme Regulation, 5, 409-437.

Kreutz, F. H. (1962). Enzymatische Glycerinbestimmung. Klinische Wochenschrift, 40, 362-363.

Kris, A. O., Miller, R. E., Wherry, F. E., and Mason, J. W. (1966). Inhibition of insulin secretion by infused epinephrine in Rhesus monkeys. Endocrinology, 78, 87-97.

Lillie, R. D., and Ashburn, L. L. (1943). Supersaturated solutions of fat stains in dilute isopropanol for demonstration of acute fatty degenerations not shown by Herxheimer technic. Archives of Pathology, 36, 432-435.

Luft, R., Ikkos, D., Palmieri, G., Ernster, L., and Afzelius, B. (1962). A case of severe hypermetabolism of nonthyroid origin with a defect in the maintenance of mitochondrial respiratory control. Journal of Clinical Investigation, 41, 1776-1804.

Morgan, C. R., and Lazarow, A. (1963). Immunoassay of insulin: two antibody system. Diabetes, 12, 115-126.

Morgan-Hughes, J. A., and Mair, W. G. P. (1973). Atypical muscle mitochondria in oculoskeletal myopathy. Brain, 96, 215-224.

Nachlas, M. M., Crawford, D. T., and Seligman, A. M. (1957). The histochemical demonstration of leucine aminopeptidase. Journal of Histochemistry and Cytochemistry, 5 , 264-278.

Padykula, H. A., and Herman, E. (1955a). Factors affectin the activity of adenosine triphosphatase and other phosen phatases as measured by histochemical techniques. Journat of Histochemistry and Cytochemistry, 3, 161-169.

Padykula, H. A., and Herman, E. (1955b). The specificity of the histochemical method for adenosine triphosphatase Journal of Histochemistry and Cytochemistry, 3, 170-195.

Porte, D., Jr, and Williams, R. H. (1966). Inhibition of insulin release by norephinephrine in man. Science, 152 1248-1250.

Seligman, A. M., and Rutenburg, A. M. (1951). The histog chemical demonstration of succinic dehydrogenase Science, 113, 317-320.

Shafiq, S. A., Milhorat, A. T., and Gorycki, M. A. (1967). Giant mitochondria in human muscle with inclusions. Archives of Neurology, 17, 666-671.

Shy, G. M., Gonatas, N. K., and Perez, M. (1966). Two childhood myopathies with abnormal mitochondria. 1. Megaconial myopathy. 2. Pleoconial myopathy. Brain, 89, 133-158.

Takeuchi, T., and Kuriaki, H. (1955). Histochemical detection of phosphorylase in animal tissues. Journal of Histochemistry and Cytochemistry, 3, 153-160.

Williamson, D. H., Mellanby, J., and Krebs, H. A. (1962). Enzymic determination of $\mathrm{D}(-)-\beta$-hydroxybutyric acid and acetoacetic acid in blood. Biochemical Journal, 82, 90-96.

Williamson, D. H., Lund, P., and Krebs, H. A. (1967). The redox state of free nicotinamide-adenine dinucleotide in the cytoplasm and mitochondria of rat liver. Biochemical Journal, 103, 514-517.

Worsfold, M., Park, D. C., and Pennington, R. J. (1973). Familial 'mitochondrial' myopathy. A myopathy associated with disordered oxidative metabolism in muscle fibres. Part 2. Biochemical findings. Journal of the Neurological Sciences, 19, 261-274. 